\title{
In vitro formation of a catabolic plasmid carrying Klebsiella pneumoniae DNA that allows growth of Escherichia coli K-12 on 3-hydroxybenzoate
}

\author{
Neil D. Robson, $\nmid$ Suzanne Parrott and Ronald A. Cooper \\ Author for correspondence: Ronald A. Cooper. Tel: +44 116252 3455. Fax: +44 1162523369.
}

Department of Biochemistry, University of Leicester, Leicester LE1 7RH, UK

\begin{abstract}
The four enzymes needed to convert 3-hydroxybenzoate to pyruvate and fumarate via the gentisate pathway, as well as a putative positive regulator protein, were encoded on an 8 kb Sphl fragment of Klebsiella pneumoniae DNA. The five genes were clustered in the order regulator-gentisate dioxygenase-fumarylpyruvate hydrolase-3-hydroxybenzoate monooxygenase-maleylpyruvate isomerase (mhbRDHMI), with the catabolic genes transcribed in the dioxygenase to isomerase direction. 2-Hydroxybenzoate was found to be a non-metabolizable inducer analogue for the mhb genes, supporting the view that gentisate rather than maleylpyruvate was the physiological inducer. The plasmid pNDR2O encoding the full gentisate catabolic pathway endowed Escherichia coli with the ability to grow on 3-hydroxybenzoate but the host cell appeared to be responsible for substrate uptake.
\end{abstract}

Keywords: Klebsiella pneumoniae, Escherichia coli, gentisate pathway enzymes, gene order, cloning

\section{INTRODUCTION}

The bacterial catabolism of 3-hydroxybenzoate can involve either 3,4-dihydroxybenzoate or 2,5-dihydroxybenzoate as the ring fission intermediate, depending on the organism (Wheelis et al., 1967). 3,4Dihydroxybenzoate can be catabolized via either the $\beta$ ketoadipate pathway or the $\alpha$-ketoacid pathway of aromatic degradation, the genes and enzymes of which have been investigated extensively (Harayama \& Timmis, 1989). 2,5-Dihydroxybenzoate is an intermediate in the gentisate pathway of aromatic degradation (Fig. 1); although this pathway has been identified in a variety of soil bacteria (Dagley, 1975) and in the enteric bacteria Klebsiella pneumoniae (Jones \& Cooper, 1990) and Salmonella typhimurium (Goetz \& Harmuth, 1992) little is known about the pathway genes.

In this paper we report the cloning, partial analysis and expression in Escherichia coli of the K. pneumoniae 3hydroxybenzoate catabolic genes, whose presence endows

\footnotetext{
† Present address: University of Cambridge, Department of Biochemistry, Tennis Court Road, Cambridge, CB2 1QW, UK

The SWISS-PROT accession number for the $\mathrm{N}$-terminal sequence reported in this paper is $\mathrm{P} 80580$.
}

E. coli with the ability to grow at the expense of 3hydroxybenzoate.

\section{METHODS}

Plasmids, bacterial strains and growth conditions. pBR322 (Soberon et al., 1980) and pUC18/19 (Norrander et al., 1983) were used as vectors for DNA cloning with $E$. coli $\mathrm{K}-12$ strains NM522 (Gough \& Murray, 1983) and 5K (Hubacek \& Glover, 1970 ) as hosts. The K. pneumoniae M5a1 strain and the details of cell culture have been described previously (Jones \& Cooper, 1990).

Enzyme assays. Methods for the preparation of cell-free extracts and assay of gentisate pathway enzymes have been described (Jones \& Cooper, 1990).

Purification of $K$. pneumoniae maleylpyruvate isomerase (EC 5.2.1.4). Ultracentrifuged crude extract was prepared in $20 \mathrm{mM}$ Tris/ $\mathrm{HCl}$ buffer $\mathrm{pH} 7 \cdot 1$ as described previously (Jones \& Cooper, 1990). This crude extract $(25 \mathrm{ml} ; 175 \mathrm{mg}$ protein) was treated at $0{ }^{\circ} \mathrm{C}$ with protamine sulphate solution $\left(40 \mathrm{mg} \mathrm{ml}^{-1}\right)$ at a ratio of $1 \mathrm{mg}$ protamine sulphate for each $5 \mathrm{mg}$ bacterial protein and the resulting precipitate removed by centrifugation at $25000 \mathrm{~g}$ and $4{ }^{\circ} \mathrm{C}$. The supernatant was treated again with the same amount of protamine sulphate and the resulting precipitate removed by centrifugation. For purification by FLPC at $22^{\circ} \mathrm{C}$ the supernatant was applied to a Mono Q HR 10/10 anion-exchange column equilibrated with 


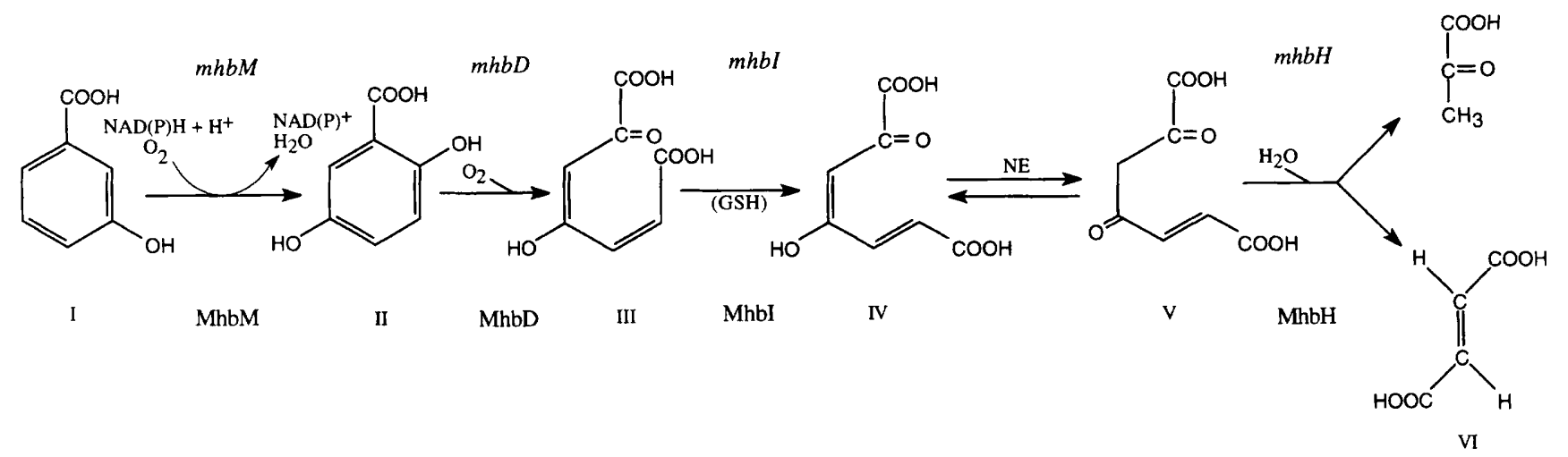

Fig. 1. The gentisate pathway for 3-hydroxybenzoate catabolism. 3-Hydroxybenzoate (I) is converted to fumarate (VI) and pyruvate (VII) via 2,5-dihydroxybenzoate [gentisate] (II), maleylpyruvate [enol] (III), fumarylpyruvate [enol] (IV) and fumarylpyruvate $(V)$ by the sequential action of 3-hydroxybenzoate monooxygenase (MhbM), 2,5-dihydroxybenzoate dioxygenase (MhbD), maleylpyruvate isomerase (Mhbl), a non-enzymic (NE) keto-enol tautomerization and fumarylpyruvate hydrolase $(\mathrm{MhbH})$.

$20 \mathrm{mM}$ Tris/ $\mathrm{HCl}$ buffer $\mathrm{pH} 7 \cdot 1$. The material that did not bind to the column included the maleylpyruvate isomerase. This material was dialysed against $20 \mathrm{mM}$ Tris/ $\mathrm{HCl}$ buffer $\mathrm{pH} 7 \cdot 5$ and reapplied to the Mono Q HR10/10 column equilibrated with this buffer. The maleylpyruvate isomerase now bound to the column and an $80 \mathrm{ml}$ gradient of $0-1 \mathrm{M} \mathrm{NaCl}$ in $20 \mathrm{mM}$ Tris/HCl buffer $\mathrm{pH} 7 \cdot 5$, at a flow rate of $8 \mathrm{ml} \mathrm{min}^{-1}$, was used as eluant and fractions of $8 \mathrm{ml}$ collected. The maleylpyruvate isomerase was eluted at $0.06 \mathrm{M} \mathrm{NaCl}$. The peak maleylpyruvate isomerase fraction was made $1 \mathrm{M}$ with respect to ammonium sulphate and applied to a Phenyl Superose HR 5/5 column equilibrated with $50 \mathrm{mM}$ potassium phosphate buffer $\mathrm{pH} 7 \cdot 1$ containing $1 \mathrm{M}\left(\mathrm{NH}_{4}\right)_{2} \mathrm{SO}_{4}$. The $\left(\mathrm{NH}_{4}\right)_{2} \mathrm{SO}_{4}$ concentration was reduced to zero over a $15 \mathrm{ml}$ gradient at a flow rate of $1 \mathrm{ml} \mathrm{min}^{-1}$ and fractions of $1 \mathrm{ml}$ collected. The maleylpyruvate isomerase was eluted at $0.35 \mathrm{M}\left(\mathrm{NH}_{4}\right)_{2} \mathrm{SO}_{4}$. A sample $(200 \mu \mathrm{l})$ of the peak fraction was applied to a Superose 12 HR 10/30 gel filtration column equilibrated against $50 \mathrm{mM}$ potassium phosphate $\mathrm{pH} 7 \cdot 1$ containing $0 \cdot 15 \mathrm{M} \mathrm{NaCl}$, eluted at a flow rate of $0.2 \mathrm{ml} \mathrm{min}^{-1}$ and fractions of $0.5 \mathrm{ml}$ collected.

Molecular-mass estimations. Subunit molecular masses were estimated by SDS-PAGE (Laemmli, 1970). The FPLC gelfiltration step was also used to estimate the native molecular mass of the maleylpyruvate isomerase. The Superose 12 column was calibrated using bovine serum albumin $(66 \mathrm{kDa})$, egg albumin $(45 \mathrm{kDa})$, carbonic anhydrase $(29 \mathrm{kDa})$ and $\alpha$-lactalbumin $(14 \cdot 2 \mathrm{kDa})$.

$\mathbf{N}$-terminal sequencing. The purified maleylpyruvate isomerase was run on a $7.5-20 \%$ SDS-polyacrylamide gel, then electroblotted onto a PVDF membrane (Matsudaira, 1987) using $50 \mathrm{mM}$ glycine $/ 50 \mathrm{mM}$ Tris $\mathrm{pH} 10$ and stained with Coomassie brilliant blue R-250. A portion of the stained $25 \mathrm{kDa}$ protein was excised and loaded into an Applied Biosystems 470 A gasphase sequencer without polybrene.

DNA manipulations. $K$. pneumoniae chromosomal DNA was prepared by the method of Chow et al. (1977). Small-scale plasmid preparations were carried out as described by Sambrook et al. (1989). Restriction endonucleases, T4 DNA ligase, and an exonuclease III deletion kit were used according to the manufacturer's instructions. DNA fragments in low-meltingpoint agarose gels were isolated as described by Perbal (1988).
Transformations were carried out using MOPS- $\mathrm{RbCl}$ (Kushner, 1978).

Chemicals and biochemicals. Oligodeoxyribonucleotides were made with an Applied Biosystems model 380B DNA synthesizer using cyanoethyl-phosphoramidite chemistry. Restriction endonucleases were from Gibco-BRL; the kit for exonuclease III deletion was from Pharmacia. All other chemicals were of the highest purity available commercially.

\section{RESULTS AND DISCUSSION}

\section{Maleylpyruvate isomerase $\mathrm{N}$-terminal amino acid sequence}

The maleylpyruvate isomerase eluted from the gel filtration column in the last step of the purification as a single symmetrical peak corresponding to a molecular mass of $30 \pm 2 \mathrm{kDa}$. Analysis of this peak by SDS-PAGE (Laemmli, 1970) showed a single major band of $25 \mathrm{kDa}$ that accounted for at least $90 \%$ of the protein present. The N-terminal sequence of this $25 \mathrm{kDa}$ protein was found to be: Met-Lys-Leu-Tyr-Ser-Phe-Phe-Asn-XaaArg-Ala. This sequence has been entered in the SWISSPROT protein sequence database under the accession number P80580.

\section{Isolation of a maleylpyruvate-isomerase-encoding clone}

A 23-mer oligodeoxyribonucleotide corresponding to the first eight residues of the $\mathrm{N}$-terminal amino acid sequence was synthesized, using inosine for the third position of the leucine codons and for the second and third positions of the serine codons. Only the first two bases for the asparagine codons were used, to keep the number of different sequence combinations to 64 .

The ${ }^{32}$ P-labelled degenerate oligodeoxyribonucleotide was used in a dot-blot to probe a size-fractionated HindIII total digest of $K$. pneumoniae M5a1 chromosomal DNA. A 


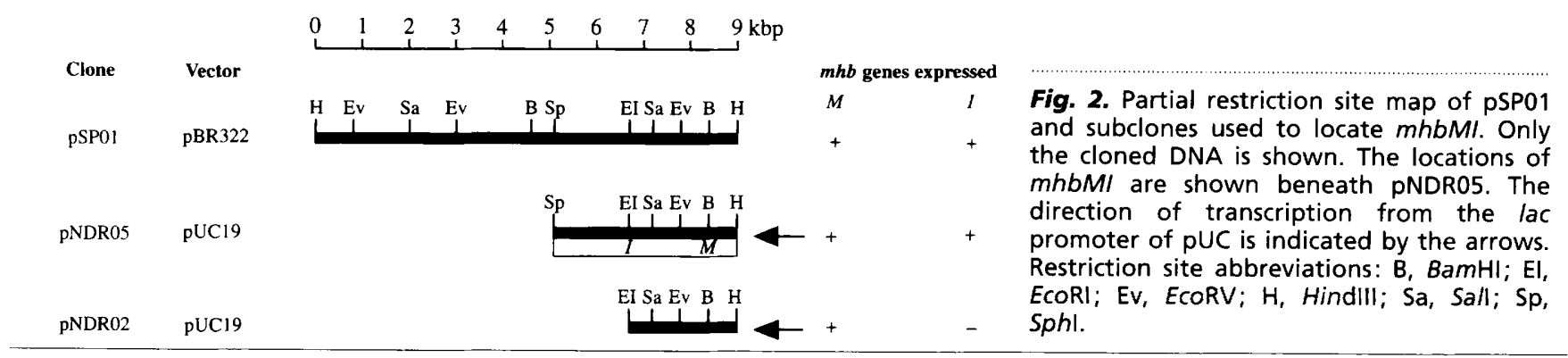

fraction corresponding to approximately $10 \mathrm{~kb}$ fragments gave the strongest signal and this DNA was ligated into HindIII-digested pBR322. After transformation into $E$. coli strain $5 \mathrm{~K}$, ampicillin-resistant colonies were probed with the labelled oligodeoxyribonucleotide and those showing strong hybridization identified. Plasmid DNA was isolated from a selection of 12 such colonies and was analysed by digestion with HindIII. Each isolate carried a $9 \mathrm{~kb}$ HindIII insert. Digestion with EcoRI gave either two approximately $7 \mathrm{~kb}$ bands (four colonies) or an $11 \mathrm{~kb}$ band plus a $3 \mathrm{~kb}$ band (eight colonies). These patterns suggested that the HindIII fragment had been incorporated in the two possible orientations.

The 12 isolates were grown in Luria-Bertani medium containing ampicillin and 3-hydroxybenzoate. Maleylpyruvate isomerase activity was found in cell-free extracts of all 12 clones, with the amount dependent on the orientation of the HindIII fragment. The group of four clones showed 5-10 times higher activity than the group of eight clones. A clone from the highest activity group was selected and its plasmid designated pSP01. A partial restriction site map of pSP01 is shown in Fig. 2.

Cell-free extracts were prepared from E. coli $5 \mathrm{~K}$ (pSP01) grown on glycerol minimal medium in the presence of ampicillin with or without 3-hydroxybenzoate. The maleylpyruvate isomerase activity was high and was not increased by growth in the presence of 3-hydroxybenzoate (data not shown). The extracts also showed 3hydroxybenzoate monooxygenase activity but none of the other gentisate pathway enzymes could be detected.

A 4 kb SpbI-HindIII subclone (Fig. 2, coordinates 5-9; pNDR05) of pSP01 still expressed the two 3hydroxybenzoate catabolic enzymes of the original plasmid but a $2.5 \mathrm{~kb}$ EcoRI-HindIII subclone (Fig. 2, coordinates $6 \cdot 5-9 \cdot 0$; pNDR02) expressed only the monooxygenase activity, suggesting that the EcoRI site was within the maleylpyruvate isomerase gene (mbbI) (Fig. 2).

To determine the direction of transcription of the two $m b b$ genes, pNDR05 was introduced into E. coli NM522 $\left(\right.$ lac $\left.I^{\mathrm{q}}\right)$ and the cells grown on glycerol minimal medium with or without IPTG. The activity of the monooxygenase and isomerase in cell-free extracts was increased six- to sevenfold when IPTG was present (data not shown), suggesting that the genes were transcribed in the same direction as the lac promoter, that is HindIII to SphI.

\section{3-Hydroxybenzoate catabolism by E. coli 5K(pSP01)}

Growth of $5 \mathrm{~K}(\mathrm{pSP} 01)$ on glycerol in the presence of 3hydroxybenzoate led to a brown coloration of the medium, which was probably due to the spontaneous oxidation of accumulated 2,5-dihydroxybenzoate (gentisate) to give melanin-like substances. The conversion of 3-hydroxybenzoate to gentisate was monitored by spectrophotometric scans of culture supernatants, and a shift from a peak absorbance at $290 \mathrm{~nm}$ due to 3 hydroxybenzoate to a peak absorbance at $322 \mathrm{~nm}$ corresponding to that of gentisate was seen. The culture supernatant could be used in place of authentic gentisate in a gentisate dioxygenase assay, supporting the suggestion that gentisate was being accumulated. 5K(pNDR02) grown under the same conditions also converted 3hydroxybenzoate to gentisate. This showed that 3hydroxybenzoate could enter $E$. coli cells and suggested that a clone carrying all the 3-hydroxybenzoate catabolic genes may endow E. coli with the novel metabolic ability of growth on 3-hydroxybenzoate.

\section{Cloning the 3-hydroxybenzoate catabolic pathway genes}

The monooxygenase and isomerase genes were located together at the $S p h$ I end of the HindIII insert fragment of pSP01 (Fig. 2), but the other 3-hydroxybenzoate catabolic pathway genes were apparently absent. If all the genes were clustered together the DNA fragment present in pNDR05 would need to be 3-4 kb larger to ensure that, additionally, the dioxygenase, hydrolase and regulatory genes were also present. To see if a single $S p h I$ fragment was large enough to include all the genes, $K$. pneumoniae DNA was digested with $S p b I$ and a Southern blot probed with the $2.5 \mathrm{~kb} E c o \mathrm{RI}-H$ indIII fragment that included the monooxygenase gene (Fig. 2). A single fragment of around $9 \mathrm{~kb}$ was detected, indicating that $5 \mathrm{~kb}$ of flanking DNA was present. To clone this fragment $S p h$ I-digested DNA was run on an agarose gel and the region corresponding to DNA of $8-15 \mathrm{~kb}$ was excised and extracted. The resulting DNA was ligated into SphIdigested pBR322 and ampicillin-resistant colonies isolated after transformation into E. coli $5 \mathrm{~K}$. Two Luria-Bertaniampicillin plates with $200-300$ colonies per plate were replica-plated onto 3-hydroxybenzoate minimal plates and, after overnight incubation at $30^{\circ} \mathrm{C}$, three strongly growing colonies were seen. One of these was selected 


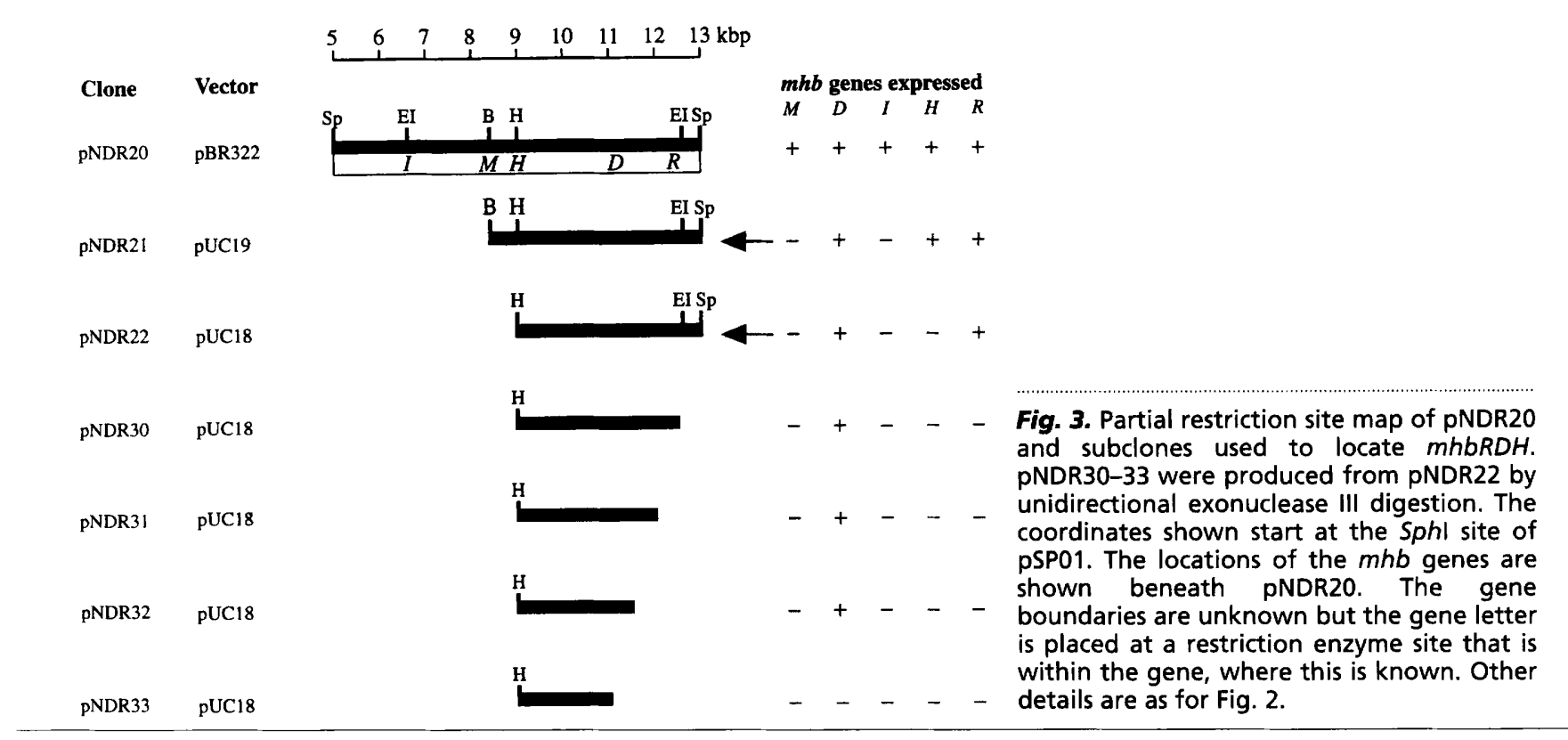

Table 1. Activities of gentisate pathway enzymes in cell-free extracts

Activities [ $\left.\mathrm{U}(\mathrm{mg} \text { protein })^{-1}\right]$ are representative values from at least three independent estimations. Enzymes: MhbM, 3-hydroxybenzoate monooxygenase (EC 1.14.13.24); MhbD, gentisate dioxygenase (EC 1.13.11.4); MhbI, maleylpyruvate isomerase (EC 5.2.1.4); $\mathrm{MhbH}$, fumarylpyruvate hydrolase (EC 3.7.1.-).

\begin{tabular}{|clccccc|}
\hline Bacterial strain & \multicolumn{1}{c}{ Growth substrate } & \multicolumn{4}{c|}{ Enzyme activity } \\
\cline { 5 - 7 } & & MhbM & MhbD & MhbI & MhbH \\
\hline Escherichia coli & & & & & \\
5K(pBR322) & Glycerol & $<0.001$ & $<0.001$ & $<0.001$ & $<0.001$ \\
5K(pNDR20) & Glycerol & 0.02 & 0.08 & 0.03 & 0.09 \\
5K(pNDR20) & Glycerol+3-hydroxybenzoate & 0.14 & 0.64 & 0.36 & 0.80 \\
5K(pNDR20) & 3-Hydroxybenzoate & 0.30 & 1.42 & 0.42 & 1.01 \\
K. preumoniae & 3-Hydroxybenzoate & 0.17 & 1.15 & 0.24 & 0.60 \\
\hline
\end{tabular}

and a plasmid designated pNDR20 containing an $S p h \mathrm{I}$ insert of $8 \mathrm{~kb}$ was obtained (Fig. 3).

Cell-free extracts were prepared from E. coli $5 \mathrm{~K}$ (pNDR20) grown on glycerol minimal medium in the presence of ampicillin with or without 3-hydroxybenzoate. As can be seen in Table 1, all four gentisate pathway enzymes were active in the glycerol-grown cells and their activities were increased 7-12 times in the presence of 3hydroxybenzoate. Activities were undetectable in equivalent extracts prepared from $E$. coli $5 \mathrm{~K}$ (pBR322).

\section{Mapping of the $\boldsymbol{m h b}$ genes}

A $4.6 \mathrm{~kb}$ Bam HI- - pphI subclone (Fig. 3, coordinates 8.4-13; pNDR21) of pNDR20 expressed the two gentisate pathway enzymes that were not expressed from pSP01. The $4.0 \mathrm{~kb}$ HindIII-SpbI subclone (Fig. 3, coordinates 9-13; pNDR22) of pNDR21 expressed only the dioxy- genase gene, indicating that the HindIII site was within the fumarylpyruvate hydrolase gene $(m b b H)$. The gene order deduced from pSP01 and pNDR20 was therefore mbbDHMI.

Although the mbb genes of pNDR20 were induced by 3-hydroxybenzoate, locating the regulatory gene was complicated by the fact that the actual inducer appeared to be gentisate or maleylpyruvate rather than 3hydroxybenzoate, and that accumulated maleylpyruvate was toxic to cells (Jones \& Cooper, 1990). Hence it was not possible to test the inducibility of the hydrolase and dioxygenase genes encoded on pNDR21 by addition of gentisate because the maleylpyruvate, formed by the dioxygenase, could not react further and so led to growth inhibition. To overcome this problem 2-hydroxybenzoate was used as a gratuitous inducer. When E. coli $5 \mathrm{~K}$ (pNDR22) was grown on glycerol in the presence of $5 \mathrm{mM}$ 2-hydroxybenzoate, dioxygenase specific activity 
Table 2. Influence of host strain on gentisate dioxygenase activity expressed from various plasmids

Crude extracts were prepared from glycerol-grown cells; activities [U (mg protein $\left.)^{-1}\right]$ are

representative values from a minimum of three separate estimations. Plasmids are described in Fig. 3 and the text. ND, Not determined.

\begin{tabular}{|c|c|c|c|c|c|c|}
\hline \multirow{2}{*}{$\begin{array}{l}\text { Host } \\
\text { strain }\end{array}$} & \multirow[t]{2}{*}{ Inducer* } & \multicolumn{5}{|c|}{ Gentisate dioxygenase (MhbD) activity } \\
\hline & & pNDR22 & pNDR30 & pNDR31 & pNDR32 & pNDR932 \\
\hline $5 \mathrm{~K}$ & - & $0 \cdot 29$ & $7 \cdot 2$ & $11 \cdot 7$ & $15 \cdot 9$ & ND \\
\hline $5 \mathrm{~K}$ & + & $2 \cdot 03$ & $5 \cdot 2$ & $8 \cdot 3$ & $17 \cdot 9$ & ND \\
\hline NM522 & - & 0.36 & $0 \cdot 49$ & $0 \cdot 47$ & 0.56 & $0 \cdot 38$ \\
\hline NM522 & + & $3 \cdot 31$ & $0 \cdot 80$ & $0 \cdot 54$ & 0.69 & $0 \cdot 35$ \\
\hline
\end{tabular}

*2-Hydroxybenzoate $(5 \mathrm{mM})$.

increased sevenfold (Table 2). To locate the regulatory gene the insert DNA of pNDR22 was digested from the $S p h I$ end with exonuclease III to produce a series of deletions. Plasmid pNDR30, in which some DNA within coordinates $12-13$ (Fig. 3) was deleted, with E. coli $5 \mathrm{~K}$ as host, gave a very high dioxygenase specific activity during growth on glycerol which decreased slightly, rather than increased, when 2-hydroxybenzoate was included (Table 2). Deletion of DNA to coordinate 11 (pNDR33, Fig. 3) resulted in loss of dioxygenase activity, so defining the end of $m b b R$ on the assumption that $m b b D$ and $m b b R$ are immediately adjacent genes. This loss of regulation meant that the relative order of the 3-hydroxybenzoate catabolic structural and regulatory genes was established as $m b b R D H M I$.

\section{Mode of action of the regulatory gene}

With E.coli $5 \mathrm{~K}$ as host, plasmids with increasing deletions upstream of the dioxygenase gene, whose $5^{\prime}$ end was therefore being brought closer to the pUC18 lac promoter, produced correspondingly greater activities of dioxygenase (Table 2). This apparent high constitutive expression in the absence of the regulator gene could indicate negative control. However, strain $5 \mathrm{~K}$ contains the normal lacI gene, whose product would be unable to interact effectively with the regulatory regions of all the copies of the pUC18 plasmid, thereby leading to apparent high constitutive production of the dioxygenase due to its expression via the thus unregulated lac promoter. However, when the various plasmid deletions were introduced into E. coli NM522 expressing the lac $I^{\mathrm{q}}$ super-repressor gene, the amounts of dioxygenase produced were much reduced and were not affected significantly by increasing deletion (Table 2). That the dioxygenase expression in strain NM522 as host occurred mainly from the $m b b$ promoter region rather than from the vector promoter was shown by the $m b b D$ expression seen after re-cloning the insert fragment of pNDR32 into pUC19 to produce PNDR932. This reversed the orientation of the insert fragment with respect to the lac promoter of the vector such that their directions of transcription would now be opposed. These results showed low, constitutive expression of $m b b D$ in the absence of the regulator gene $m b b R$, compatible with the regulator gene encoding a positive activator of $m b b$ structural gene expression.

\section{Comparison of 3-hydroxybenzoate catabolism by $K$. pneumoniae with that of $E$. coli expressing the $m h b$ genes}

pNDR20 endowed $E$. coli $5 \mathrm{~K}$ with a novel ability to grow at the expense of 3-hydroxybenzoate. The effectiveness of this was assessed by comparing 3-hydroxybenzoate catabolism of E. coli $5 \mathrm{~K}$ (pNDR20) with that of $K$. pneumoniae M5a1. During exponential growth the doubling time $\left(t_{\mathrm{d}}\right)$ for $5 \mathrm{~K}$ (pNDR20) was $118 \mathrm{~min}$, which was about $50 \%$ greater than for $\mathrm{M} 5 \mathrm{a} 1\left(t_{\mathrm{d}}=72 \mathrm{~min}\right)$. Cell-free extracts were assayed for the 3-hydroxybenzoate catabolic enzymes to seek an explanation of this slightly slower growth rate. Table 1 shows that the activities from $E$. coli $5 \mathrm{~K}$ (pNDR20) were slightly greater than those of $K$. pneumoniae M5a1. However, in addition to the catabolic enzymes, uptake of 3-hydroxybenzoate is required for growth. Since pNDR02, which encodes the complete monooxygenase gene and parts of the isomerase and hydrolase genes, is theoretically too small also to encode a permease but nevertheless still endows $E$. coli $5 \mathrm{~K}$ cells with the ability to convert 3-hydroxybenzoate to gentisate, it seems that uptake must be a property of the E. coli host. Which $E$. coli permease is involved is unknown but the general or specific aromatic amino acid uptake systems or the various systems for the uptake of the catechol siderophore enterochelin are likely contenders. Thus, the limiting factor that accounts for the somewhat slower growth on 3-hydroxybenzoate of $E$. coli $5 \mathrm{~K}$ (pNDR20) compared to $K$. pneumoniae M5a1 may be the rate of substrate uptake.

\section{ACKNOWLEDGEMENTS}

We are indebted to $\mathrm{Dr} \mathrm{M}$. Davison for the amino acid sequencing, $\mathrm{Mr}$ J. Keyte for oligodeoxyribonucleotide synthesis, Mr J. M. Stringfellow for drawing the figures and Mrs 
U. Gervind-Richards for producing the manuscript. N.D.R. thanks the Science and Engineering Research Council for a research studentship.

\section{REFERENCES}

Chow, L. T., Kahmann, R. \& Kemp, D. (1977). Electron microscopic characterisation of DNAs of non-defective deletion mutants of bacteriophage Mu. J Mol Biol 155, 113-121.

Dagley, S. (1975). A biochemical approach to some problems of environmental pollution. In Essays in Biochemistry, vol. 11, pp. 81-138. Edited by P. N. Campbell \& W. N. Aldridge. London, New York \& San Francisco: Academic Press.

Goetz, F.E. \& Harmuth, L. J. (1992). Gentisate pathway in Salmonella typhimurium: metabolism of $m$-hydroxybenzoate and gentisate. FEMS Microbiol Lett 97, 45-50.

Gough, J. A. \& Murray, N. E. (1983). Sequence diversity among related genes for recognition of specific targets in DNA molecules. J Mol Biol 166, 1-19.

Harayama, S. \& Timmis, K. N. (1989). Catabolism of aromatic hydrocarbons by Pseudomonas. In Genetics of Bacterial Diversity, pp. 151-174. Edited by D. A. Hopwood \& K. E. Chater. New York: Academic Press.

Hubacek, J. \& Glover, S. W. (1970). Complementation analysis of temperature-sensitive host specificity mutations in Eschericbia coli $\mathrm{C}$. $J$ Mol Biol 50, 111-127.

Jones, D. C. N. \& Cooper, R. A. (1990). Catabolism of 3hydroxybenzoate by the gentisate pathway in Klebsiella pneumoniae M5a1. Arch Microbiol 154, 489-495.
Kushner, S. R. (1978). An improved method for the transformation of Escherichia coli with ColE1-derived plasmids. In Genetic Engineering, pp. 17-23. Edited by H. B. Boyer \& S. Nicosia. Amsterdam: Elsevier.

Laemmli, U. K. (1970). Cleavage of structural proteins during the assembly of the head of bacteriophage T4. Nature 227, 680-685.

Matsudaira, P. (1987). Sequence from picomole quantities of proteins electroblotted onto polyvinylidene difluoride membranes. J Biol Chem 262, 10035-10038.

Norrander, J., Kempe, T. \& Messing, J. (1983). Construction of improved M13 vectors using oligonucleotide-directed mutagenesis. Gene 26, 101-106.

Perbal, B. (1988). A Practical Guide to Molecular Cloning, pp. 368-374. Chichester: John Wiley.

Sambrook, J., Fritsch, E. F. \& Maniatis, T. (1989). Molecular Cloning: a Laboratory Manual, 2nd edn. Cold Spring Harbor, NY: Cold Spring Harbor Laboratory.

Soberon, X., Covarrubias, L. \& Bolivar, F. (1980). Construction and characterisation of new cloning vehicles. IV. Deletion derivatives of pBR322 and pBR325. Gene 9, 287-305.

Wheelis, M. L., Palleroni, N. J. \& Stanier, R. Y. (1967). The metabolism of aromatic compounds by Pseudomonas testosteroni and P. acidovorans. Arch Mikrobiol 59, 302-314.

Received 27 February 1996; revised 22 April 1996; accepted 24 April 1996. 